\title{
School Psychology in Portugal: Practitioners' Characteristics and Practices
}

\author{
Sofia A. Mendes and Isabel Abreu-Lima \\ Faculty of Psychology and Educational Sciences, University of Porto, Centre of Psychology, Porto, Portugal \\ Leandro S. Almeida \\ Department of Educational Psychology and Special Education, University of Minho, Braga, Portugal \\ Rune J. Simeonsson \\ School Psychology Program, School of Education, University of North Carolina, Chapel Hill, North Carolina, USA
}

\begin{abstract}
Little empirical evidence is available on the professional characteristics and practices of school psychologists in Portugal. This study surveyed a total of 477 Portuguese school psychologists employed in public $(80 \%)$ and private schools $(20 \%)$. Portuguese school psychologists are described with regard to demographic, professional, and educational backgrounds, school settings, roles performed, and main target populations served. Evaluating and counseling regular education students, vocational guidance, and special education-related activities emerged as the most time-consuming professional practices. A professional practice primarily focused on students, mainly from the highest education levels, was also observed. Results are compared with findings of previous surveys and reviewed in the context of the current literature on the school psychologist's role. Implications for the field are also provided.
\end{abstract}

Keywords: School psychology, school-based mental health services, professional issues, practice issues, survey research

Portugal has a relatively short history of delivering psychological services in schools, with psychologists entering the education system mainly in response to three emerging needs (Almeida, 2003): (a) the inclusion of children with special education needs, (b) the creation of vocational training programs in secondary schools, and (c) the promotion of school success for at-risk children during elementary education. Only in the mid-1980s, after the approval of the Education Act (Decree-law n ${ }^{\circ}$ 46/86), was the provision of psychological services for all students officially recognized as an important dimension of the educational process. Subsequently, school psychology services were created through legislation in 1991, established on an experimental basis in 1993, expanded

Submitted July 3, 2013; accepted October 31, 2013.

Correspondence should be addressed to Sofia A. Mendes, Faculdade de Psicologia e Ciência de Educação, Rua Alfredo Allen, Sala FPCE136, 4200-135, Porto, Portugal. E-mail: sofia.a.mendes@gmail.com and made official in 1996-1997; they have been under the responsibility of the Ministry of Education since then.

Conceived as part of the school network, school psychology services are provided at preschool, elementary, and secondary school levels. Preschool education is aimed at children aged 3 to 5 and is not mandatory. Elementary education spans 9 years divided into three cycles: first cycle (1st to 4th grades), second cycle (5th and 6th grades), and third cycle ( 7 th to 9 th grades). Secondary education covers the 3 years between the 10th and 12th grades and marks the end of compulsory education. Special education and vocational training are available within the school system, both in public and private schools.

Major responsibilities for these services defined by law (Decree-law $n^{\circ}$ 190/91) are to (a) contribute to students' integral development and identity construction; (b) support students' learning process and integration; (c) provide psychological and psychopedagogical support to students, parents, and school staff; (d) cooperate in the assessment 
and support of students with special educational needs; (e) help identify students' interests and abilities; (f) develop vocational guidance activities; and $(\mathrm{g})$ collaborate in the provision of in-service training and research activities. Current legislation states that technical teams of school psychology services can be formed by psychologists, vocational counselors, and/or social workers, but typically these services are provided by a psychologist.

Each school psychology service may cover at least one school establishment or school cluster. A school cluster is an organizational unit with its own administrative bodies made up of several school establishments, geographically dispersed, that serve children from preschool to the 9th or 12 th grades, based on a common pedagogical project. In the case of a school cluster, school psychology services are hosted in the cluster's headquarters for logistical purposes (i.e., the school building where administrative bodies are located and in which the highest education levels tend to operate) and practitioners may have to move between schools.

Since it was officially established, the Portuguese public network of school psychology services has never been expanded. Public schools are financially dependent on the government, through the Ministry of Education, and require permission from this entity to hire school psychologists. Since 2007, several schools have been authorized to hire full-time psychologists on an annual basis. However, due to the economic crisis, at the end of each school year, there are no guarantees that these positions will be maintained. A tendency has also been observed in the last few years for the Ministry of Education to hire a single school psychologist to serve more than one school cluster simultaneously. Thus, despite requirement by law, the Ministry of Education has not been able to guarantee that all public schools are covered by full-time school psychology services.

Presently, the number of psychologists providing schoolbased psychological services in public schools has not been officially determined. Nonetheless, it is estimated that there are around 400 school psychologists permanently employed (Inácio, 2012) and 250 working on a contractual basis, according to the governmental school hiring database. The total number of psychologists performing the same functions in private schools is unknown. Private schools are governed by legislation and statutes of their own, which are required to respect the Education Act. As part of their autonomy, they are responsible for selecting and recruiting school psychologists. According to Almeida (2003), in the private education sector the practice of hiring several school psychologists has been common, enabling schools to maximize the potential of school psychology services. Conversely, in the public sector, the trend has been for one school psychologist to serve increasingly numerous, diverse, and geographically dispersed school populations.

In Portugal, no psychology specialization has official recognition, and only the title "psychologist" is regulated by law (see Decree-law $n^{\circ}$ 57/2008). In order to work as a psychologist in any area of professional psychology, it is mandatory to be registered as an effective member of the Portuguese Order of Psychologists, the organization that represents and regulates psychology in Portugal. The terms school psychologist, educational psychologist, or simply psychologist are used interchangeably to designate psychologists working within the school system. For clarity and consistence, the term school psychologist is used throughout this article to refer to psychologists performing the functions and roles defined by Decree-law $n^{\circ}$ 190/91.

Similar to what has happened in other countries, the implementation of the Bologna Declaration in the Portuguese university system introduced changes in the training process of psychologists. This declaration aimed to create an overall convergence and harmonization in the European higher education system, facilitating the recognition of academic degrees and qualifications, students' mobility, and exchanges between institutions. One of the major implications of the Bologna Declaration was the agreement on a common education system based on three cycles: bachelor's degree (3 years), master's degree (2 years), and doctorate degree (3 years) (see European Commission, 2013, for further details).

Before the Bologna Declaration, the training of psychologists in Portugal was defined by three academic degree levels: licentiate ( 4 or 5 years), master ( 2 years), and doctoral (4 years). Only a licentiate degree was needed to work as a psychologist. Most universities provided a licentiate diploma in general psychology, preparing students to work in different psychology fields. However, some university programs offered opportunities for specialization as part of the curriculum, including optional courses and supervised training. Currently, with the Bologna Declaration, the training of psychologists is composed of a threeyear general education program in psychology (bachelor) plus an additional two-year period of graduate preparation (master). The master's degree level is now required to enter into the profession and allows students to specialize in a psychology field. Nevertheless, no national guidelines exist regarding psychologists' training, and programs differ in their curricula and designation.

The importance of systematically gathering information about school psychology services is recognized at national and international levels as crucial to the development of school psychology (Bramlett, Murphy, Johnson, Wallingsford, \& Hall, 2002; Oakland \& Cunningham, 1992). Survey research has a long tradition within the school psychology field and has been frequently used to study school psychology as a profession. The United States has been at the forefront of this line of research for several years, with the National Association of School Psychologists (NASP) periodically studying the field or supporting national surveys of its members since 1989 (Castillo, Curtis, \& Gelley, 2012). A wide range of articles has been published as a result of such efforts (e.g., Curtis, Grier, \& Hunley, 2003; Curtis et al., 2008; Curtis, Walker, Hunley, \& 
Baker, 1999; Lewis, Truscott, \& Volker, 2008; Reschly, 2000; Reschly \& Wilson, 1995), providing a consistent picture of school psychology in the United States and revealing distinct patterns of professional activities (Fagan \& Wise, 2007). Simultaneously, several researchers have contributed to expand the knowledge about school psychology in other countries (e.g., D'Amato, Van Schalkwyk, Zhao, \& Hu, 2013; Jordan, Hindes, \& Saklofske, 2009; Raviv, MashrakiPedhatzur, \& Erhard, 2002; Schalkwyk \& D'Amato, 2013; Trombetta, Alessandri, \& Coyne, 2008; Wang \& D'Amato, 2013), with special emphasis on the International School Psychology Survey (ISPS) developed under the leadership of Shane Jimerson and the Research Committee of the International School Psychology Association (ISPA) (see Jimerson, Graydon, Curtis, \& Staskal, 2007; Jimerson et al., 2008; Jimerson, Annan, Skokut, \& Renshaw, 2009).

A review of the literature reveals that no peer-reviewed articles about Portuguese school psychology have been published in international journals. At the national level, several articles have addressed this issue, but mostly from a theoretical and critical perspective. The Ministry of Education has conducted surveys on school psychology services (e.g., Centro Interdisciplinar de Estudos Económicos [CIDEC], 2006); however, results from these studies are not adequately disclosed. The conceptual basis of these studies and the nature of the data collected also limit comparisons with international findings (Mendes, Abreu-Lima, \& Almeida, 2013).

Therefore, the purpose of this study is to (a) identify the main characteristics of Portuguese schools psychologists, (b) describe the general conditions under which they work, (c) provide specific information on their professional practices, and (d) compare findings on an international basis. This information can contribute to the advancement of scientific knowledge about school psychology, both nationally and internationally, by providing further understanding of the current status of school psychology as a profession in Portugal. It is also of particular relevance, given that the profession and school psychology services in Portugal are in transition and that the future is uncertain. The Portuguese Order of Psychologists is working toward the creation of specialty areas in psychology, and the Ministry of Education is thinking of reorganizing school psychology services. It is hoped that the findings and implications of this study can be used to inform and guide policy makers, professional associations, practitioners, and other interested parties in their positions and actions regarding psychological practice in schools.

\section{METHOD}

\section{Participants}

A nationwide survey was conducted among school psychologists working in public and private schools.
A total of 572 surveys were initiated and 495 completed. However, 18 surveys were excluded because they were completed by psychologists who were not working as school psychology service technicians. Of the 477 school psychologists who participated in the study, $88 \%$ were women. The mean reported age was 38 years $(S D=8.36$, range $=24-61$ ). Eighty percent of practitioners worked in public schools and $20 \%$ in private schools. Taking into account the best available estimates for the total number of school psychologists working in the public education sector, it is estimated that a response rate of 59\% was obtained from among this population. Given the constraints under which data were collected from school psychologists in the private education sector, it is not possible to determine a response rate for this group.

\section{Instrument}

A survey was developed drawing on previous research in the school psychology field (e.g., Bramlett et al., 2002; CIDEC, 2006; Jimerson et al., 2007; Jordan et al., 2009; Leitão, Paixão, Silva, \& Miguel, 2001; Raviv et al., 2002; Trombetta et al., 2008) and on Web-based survey guidelines (e.g., Dillman, Smith, \& Christian, 2009). The survey focused on central aspects of the school psychologist's job and addressed topics such as personal and professional background information (e.g., sex, age, training, employment status, income, and years of experience as a school psychologist in the current school), school settings characteristics (e.g., type of educational establishment, school psychologist-to-student and school psychologist-toschool ratios), and professional practices (e.g., percentage of time spent with different activities and target populations, on an annual basis). Question formats included single- and multiple-choice items as well as open-ended questions. For a more detailed description of the development and content of the survey, see Mendes et al. (2013).

\section{Procedures}

Data were collected between May and September of 2012 using an online survey format. Given the absence of an upto-date and publicly available list of school psychologists, and organizational differences between the public and private education sector, different strategies were devised to reach participants. In public schools, the Ministry of Education disseminated the surveys' email invitation, throughout the school network, via regional structures. This invitation was addressed to the schools' boards of directors, who forwarded them to the school psychologists working in their institutions. Private schools were located using national databases, and school administrators were contacted by the authors via email. Approximately 400 private schools were contacted, without previous information on whether or not they had school psychology 
services. An accompanying hyperlink and password allowed full access to the survey. The study was also advertised among key persons and in social networking websites; however, closed access mode was used to reduce self-selection bias. The LimeSurvey online survey software, version 1.91 + build 120302, was used to implement the survey. The survey software assigned a unique identification number to each respondent, preventing multiple replies from a single user, and sent reminders and follow-up messages. It also validated responses, preventing systematic missing data and guaranteeing the quality of the data collected. Participants were also given the option to provide their email address for further contacts related to the survey, which was used exceptionally to clarify responses. Participation was rewarded with an electronic guidebook on the prevention of work-related stress in the school setting. IBM SPSS version 21.0 was used for data analysis.

\section{RESULTS}

\section{Professional Characteristics}

To better characterize and interpret the results, and considering that several of the variables in analysis present skewed distributions, four descriptive measures are provided when appropriate, among which is the interquartile range (IQR).

Respondents reported an average of 12 years of experience as a school psychologist $(S D=7.40$, $M d n=11, I Q R=17-6$ ). Twenty-four percent of the sample had been engaged in school psychology for less than 6 years, $25 \%$ for 6 to 10 years, $21 \%$ for 11 to 15 years, and $30 \%$ for more than 15 years. The mean length of experience in their current school was 8 years $(S D=6.49, M d n=7$, $I Q R=13-3)$, with respondents presenting the following distribution by category: less than 6 years (44\%), 6 to 10 years (19\%), 11 to 15 years (24\%), and more than 15 years (13\%). A strong positive correlation was found between the number of years of experience as a school psychologist and years of experience in the current school setting $(r=.80, p<.001)$. This finding suggests higher career stability, at least for more experienced school psychologists who worked in the same educational establishment over time.

\section{Employment Status and Salary}

Fifty-six percent of the respondents reported being employed under permanent contracts, $40 \%$ under fixed-term contracts and $4 \%$ working as independent contractors. Ninety-four percent were employed as full-time school psychologists. The weekly hourly schedule of a full-time school psychologist was 35 hours. Those employed on a part-
TABLE 1

School Psychologist's Employment Status and Monthly Salaries

\begin{tabular}{|c|c|c|c|c|}
\hline & \multicolumn{2}{|c|}{$\begin{array}{l}\text { Public schools } \\
\quad(n=383)\end{array}$} & \multicolumn{2}{|c|}{$\begin{array}{l}\text { Private schools } \\
\quad(n=94)\end{array}$} \\
\hline & $n$ & $\%$ & $n$ & $\%$ \\
\hline \multicolumn{5}{|l|}{ Contract type } \\
\hline Permanent & 218 & 56.9 & 48 & 51.1 \\
\hline Fix-term & 152 & 39.7 & 39 & 41.5 \\
\hline Independent contractor & 13 & 3.4 & 7 & 7.4 \\
\hline \multicolumn{5}{|l|}{ Workload } \\
\hline Full-time & 370 & 96.6 & 77 & 81.9 \\
\hline Part-time & 13 & 3.4 & 17 & 18.1 \\
\hline \multicolumn{5}{|l|}{ Monthly salaries } \\
\hline$\leq 500 €$ & 5 & 1.3 & 2 & 2.1 \\
\hline $501 €-750 €$ & 10 & 2.6 & 8 & 8.5 \\
\hline $751 €-1000 €$ & 5 & 1.3 & 21 & 22.3 \\
\hline $1001 €-1250 €$ & 163 & 42.6 & 34 & 36.2 \\
\hline $1251 €-1500 €$ & 67 & 17.5 & 15 & 16.0 \\
\hline$\geq 1501 €$ & 133 & 34.7 & 14 & 14.9 \\
\hline
\end{tabular}

time basis $(6 \%)$ reported working an average of 19 hours per week $(S D=5.82, M d n=18, I Q R=21-17)$. The distribution of respondents per sector across employment contract, workload, and salary categories is presented in Table 1.

The percentage of participants who indicated that they were working under permanent contracts, fixed-term contracts, or as independent contractors, did not differ in public and private education sectors, $\chi^{2}(2,477)=3.48$, $p=.18$. However, a higher proportion of part-time positions was found in private schools, $\chi^{2}(1,477)=25.20, p<.001$. Salary levels of the full-time school psychologists were not equally distributed in the sample, varying according to the type of educational establishment, $\chi^{2}(3,447)=55.61$, $p<.001$, and employment contract, $\chi^{2}(6,447)=355.34$, $p<.001$. The lowest salaries were more likely to be reported by those working in private schools or under fixedterm contracts, and the highest by those employed in public schools or under permanent contracts.

\section{Training Profile}

Sixty-three percent of the respondents reported holding a pre-Bologna licentiate degree, $35 \%$ a master's degree, and $2 \%$ a doctoral degree. Most of the respondents (95\%) graduated before the implementation of the Bologna Declaration. About $62 \%$ of the practitioners working under fixed-term contracts or as independent contractors reported having obtained a degree beyond the licentiate level, whereas $39 \%$ of practitioners who were permanently employed reported owning degrees beyond this level, $\chi^{2}(1,477)=31.98, p<.001$. Table 2 presents the distribution of areas of specialization for respondents at the licentiate, master, and doctoral levels. 
TABLE 2

School Psychologists by Educational Background and Area of Specialization

\begin{tabular}{|c|c|c|c|c|c|c|}
\hline & \multicolumn{2}{|c|}{$\begin{array}{l}\text { Licentiate } \\
(n=477)\end{array}$} & \multicolumn{2}{|c|}{$\begin{array}{c}\text { Master } \\
(n=174)\end{array}$} & \multicolumn{2}{|c|}{$\begin{array}{c}\text { Doctoral } \\
(n=9)\end{array}$} \\
\hline & $n$ & $\%$ & $n$ & $\%$ & $n$ & $\%$ \\
\hline Educational, developmental, vocational psychology & 205 & 43.0 & 106 & 60.9 & 3 & 33.3 \\
\hline Clinical and health psychology & 152 & 31.9 & 49 & 28.2 & 2 & 22.2 \\
\hline Other psychology fields (e.g., forensic, social and organizational psychology, etc.) & 34 & 7.1 & 17 & 9.8 & 1 & 11.1 \\
\hline Without specialization & 86 & 18.0 & 2 & 1.1 & 3 & 33.3 \\
\hline
\end{tabular}

\section{School Setting Characteristics}

The most common employment setting for school psychologists in the private education sector is the singleschool establishment (92\%), while school psychologists from public schools commonly reported serving one or more school clusters (69\%). School psychologists from public schools reported covering an average of eight school buildings $(S D=7.20, M d n=6, I Q R=11-1)$, whereas the majority of school psychologists from private schools reported serving just one $(S D=0.50, \quad M d n=1$, $I Q R=1-1)$. School psychologists working in school clusters reported dedicating an average of 23 hours per week $(S D=6.49, M d n=25, I Q R=27-20)$ to the cluster's headquarters and 11 hours $(S D=6.26, M d n=10$, $I Q R=15-7)$ to the remaining schools.

Forty-six percent of participants worked in elementary schools, $24 \%$ in secondary schools, and $30 \%$ in a combination of elementary and secondary schools. The majority of the respondents reported working in schools that provide a wide range of education levels, facing the challenge of responding to the needs of significantly different age groups. For example, $37 \%$ of the respondents reported serving children from preschool to the 9th grade, and $24 \%$ from preschool to the 12th grade. The proportion of school psychologists who worked with four or more education levels was significantly higher in public schools $(67 \%)$ than in private schools $(42 \%), \chi^{2}(1,477)=19.95$, $p<.001$.

An average school psychologist-to-student ratio of 1:1131 was reported, although wide variation was observed across schools $(S D=725.91, M d n=1: 1000$, $I Q R=1: 1500-1: 600)$. This ratio was substantially higher in public schools $(M=1: 1311, S D=678.62, M d n$ $=1: 1200, I Q R=1: 1700-1: 800)$ than in private schools $(M=1: 400, S D=363.31, M d n=1: 300, I Q R=1: 455-$ 1:197). The distribution of school psychologist-to-student ratios in public and private schools is shown in Table 3.

The NASP (NASP, 2010) states that the school psychologist-to-student ratio should not exceed 1:1000. However, when school psychologists perform a broad-based role, such as the one mandated by Portuguese law (Decreelaw $\left.n^{\circ} 190 / 91\right)$, NASP (2010) recommends that this ratio should be between 1:500 and 1:700 in order to ensure the quality of student outcomes. Using the upper value of the NASP (2010) recommended interval as a cut-off point (i.e., 1:700), chi-square analysis revealed that there were significantly more public schools $(81 \%)$ working with inadequate ratios than private schools $(13 \%), \chi^{2}(1$, $477)=158.57, p<.001$. This difference stems from two factors: public schools served on average larger student populations $(M=1424, S D=680.32, \quad M d n=1300$, $I Q R=1800-900)$ than private schools $(M=615$, $S D=497.08, \quad M d n=400, I Q R=890-250)$ and hire fewer school psychologists per school establishment $(M=1, \quad S D=0.4, \quad M d n=1, I Q R=1-1)$ compared with private schools $(M=2, S D=1.12, M d n=1$, $I Q R=2-1)$.

\section{Professional Practices}

The participants were requested to estimate how their work time was distributed by a list of common school psychology activities. Results regarding the percentage of time spent in those activities are reported in Table 4. Counseling, psychoeducational evaluation, and vocational guidance were found to be the activities to which practitioners dedicated the greatest percentage of their time.

Practitioners reported spending the majority of their time with students $(M=56 \%, S D=14.85, M d n=60 \%$, $I Q R=70-50)$, followed by teachers $(M=14 \%$,

TABLE 3

Distribution of School Psychologist-to-Student Ratio

\begin{tabular}{lrrrrr}
\hline & \multicolumn{2}{c}{$\begin{array}{c}\text { Public schools } \\
(n=383)\end{array}$} & & \multicolumn{2}{c}{$\begin{array}{c}\text { Private schools } \\
(n=94)\end{array}$} \\
\cline { 2 - 3 } & $n$ & $\%$ & & $n$ & $\%$ \\
\cline { 2 - 5 } & 13 & 3.4 & 60 & 63.8 \\
$1:<350$ & 59 & 15.4 & & 22 & 23.4 \\
$1: 351-700$ & 84 & 21.9 & & 7.4 \\
$1: 701-1050$ & 89 & 23.2 & & 3 & 3.2 \\
$1: 1051-1400$ & 50 & 13.1 & & 0 \\
$1: 1401-1750$ & 40 & 10.4 & & 1 & 1.1 \\
$1: 1751-2100$ & 48 & 12.5 & & 1 \\
$1:>2101$ & & & & 1.1 \\
\hline
\end{tabular}


TABLE 4

Percentage of Time Spent in Different Professional Activities on an Annual Basis

\begin{tabular}{lrrrr}
\hline & $M$ & $S D$ & $M d n$ & \multicolumn{1}{c}{$I Q R$} \\
\hline Counseling students & 20 & 11.27 & 20 & $25-10$ \\
Psychoeducational evaluation & 19 & 10.57 & 20 & $25-10$ \\
Vocational guidance & 18 & 11.98 & 15 & $25-10$ \\
$\quad$ Special education-related activities & 13 & 8.94 & 10 & $15-5$ \\
Promotion & 6 & 6.09 & 5 & $10-0$ \\
Prevention & 5 & 4.88 & 5 & $8-1$ \\
$\quad$ Community liaison & 4 & 3.43 & 5 & $5-2$ \\
$\quad \begin{array}{l}\text { Training and consultation to } \\
\quad \text { parents/family }\end{array}$ & 6 & 4.21 & 5 & $10-2$ \\
$\quad$ Training and consultation to & & & & \\
$\quad$ teachers/school staff & 9 & 6.85 & 8 & $13-4$ \\
$\quad$ Research & 1 & 2.06 & 0 & $2-0$ \\
\hline
\end{tabular}

$S D=6.55, M d n=14 \%, I Q R=20-10)$ and parents $(M=12 \%, S D=5.85, M d n=10 \%, I Q R=15-10)$. School psychologists spent the least amount of time with other specialists from their schools and/or local communities $(M=9 \%, S D=6.64, M d n=8 \%, I Q R=12-5)$, with the school's board of directors $(M=6 \%, S D=5.08$, $M d n=5 \%, I Q R=10-4)$, and with nonprofessional staff $(M=3 \%, S D=2.70, M d n=2 \%, I Q R=5-0)$.

Results concerning the time spent with different education levels and teaching modalities are presented in Table 5. In elementary schools, school psychologists reported spending most of their time with the highest education levels. On the other hand, in schools that combine elementary and secondary education, the lower education levels seem to consume the majority of practitioners' time. In these two types of school establishment, the percentage of time dedicated to preschool education was considerably smaller. Generally, school psychologists reported spending the majority of their time with general rather than with special education.

\section{DISCUSSION}

The purpose of this study was to examine the state of school psychology as a profession in Portugal through the distribution of a national survey. Although the status of school psychology has been explored in other countries, to date no comparable study has been made in Portugal. The findings of this study address this information gap by providing a picture of Portuguese school psychologists, their working conditions, and professional practices in 2012.

The demographic data collected demonstrate that the majority of school psychologists in Portugal are female. This trend is consistent with previous findings that point to the increasing feminization of the school psychology field in other countries (e.g., Albania, Australia, China [Hong Kong], Cyprus, Estonia, Georgia, Greece, Italy, New Zealand, Northern England, Russia, and the United States) (Jimerson et al., 2007; Jimerson et al., 2008; Jimerson et al., 2009) and of the field of psychology in general (Curtis et al., 2003). Data related to age and years of professional experience allow us to characterize Portuguese school psychologists as a relatively young professional group, with years of professional experience reflecting the practitioners' ages. The late appearance of psychology courses in Portuguese universities (late 1970s) and the late entry of psychologists into schools (early 1980s) may account for this fact. Indeed, as in preceding ISPS data, the ranges of school psychologists' ages and years of professional experience appear to be related to the number of years the profession has existed in the country (Jimerson et al., 2007).

The pre-Bologna licentiate degree was the most common academic degree held by school psychologists, followed by the master's degree. However, it is expected that this trend will be reversed in the coming years. Due to the guidelines of the Bologna Declaration and the requirements of the Portuguese Order of Psychologists, a master's degree is now mandatory to enter the profession. Nevertheless, the requirement for a higher academic degree does not

TABLE 5

Percentage of Time Spent, on an Annual Basis, With Different Education Levels and Teaching Modalities by Type of Educational Establishment

\begin{tabular}{|c|c|c|c|c|c|c|c|c|c|c|c|c|}
\hline & \multicolumn{4}{|c|}{ Elementary school $(n=217)$} & \multicolumn{4}{|c|}{ Secondary school $(n=116)$} & \multicolumn{4}{|c|}{$\begin{array}{l}\text { Elementary and secondary school } \\
\qquad(n=144)\end{array}$} \\
\hline & $M$ & $S D$ & $M d n$ & $I Q R$ & $M$ & $S D$ & $M d n$ & $I Q R$ & $M$ & $S D$ & $M d n$ & $I Q R$ \\
\hline Preschool & 9 & 10.65 & 5 & $10-2$ & & & & & 7 & 8.85 & 5 & $10-1$ \\
\hline $1 \mathrm{st}-4$ th grades & 22 & 14.31 & 20 & $30-12$ & & & & & 17 & 11.03 & 15 & $20-10$ \\
\hline 5 th -6 th grades & 25 & 13.20 & 25 & $30-20$ & & & & & 21 & 12.42 & 20 & $30-14$ \\
\hline 7th-9th grades & 28 & 14.56 & 30 & $35-20$ & 36 & 23.42 & 40 & $55-20$ & 27 & 12.99 & 25 & $30-20$ \\
\hline Vocational basic education $^{\mathrm{a}}$ & 9 & 10.08 & 10 & $10-2$ & 20 & 18.75 & 10 & $30-5$ & 9 & 7.50 & 7 & $12-5$ \\
\hline 10th-12th grades & & & & & 27 & 18.94 & 20 & $38-15$ & 9 & 9.20 & 7 & $13-2$ \\
\hline Vocational secondary education ${ }^{\mathrm{a}}$ & & & & & 30 & 29.76 & 20 & $50-10$ & 7 & 8.05 & 5 & $10-1$ \\
\hline Special education & 13 & 15.70 & 10 & $20-0$ & 12 & 11.86 & 10 & $20-0$ & 12 & 10.29 & 10 & $15-5$ \\
\hline
\end{tabular}

${ }^{\mathrm{a}}$ Concerns grades 5-9.

${ }^{\mathrm{b}}$ Concerns grades $10-12$. 
necessarily translate into an increase in education and training. After the implementation of the Bologna Declaration, 5 years of studies correspond to a master's degree, when previously this degree typically required 7 years of training.

Professionals working under temporary employment contracts generally hold a higher level of academic preparation, which may be a consequence of efforts to adapt to a more competitive and unstable job market. Since a specific training curriculum is not required for licensing as a school psychologist, a wide range of specialization areas was also observed among practitioners. This trend may change in the forthcoming years, due to the Bologna Declaration. As a consequence of this policy shift, universities are now providing students with more opportunities for specialization in school or educational psychology, which will lead to the training of specialized rather than generalist psychologists.

The employment conditions for school psychologists vary widely in public and private schools, with the former presenting more challenging conditions in terms of school psychologist-to-student ratios, number of schools, and education levels served. The average ratio of 1:1311 observed in public schools is clearly above the NASP (2010) recommended ratio of $1: 500$ to $1: 700$, with $81 \%$ of the respondents from this sector reporting to work with ratios above this interval, and $60 \%$ serving a population exceeding 1,000 students. Therefore, the high ratios found in a substantial number of public schools are of significant concern, jeopardizing the quality of the services delivered by practitioners. They may also preclude practitioners from engaging in practices that have been consistently recognized as more desirable (e.g., intervention and prevention) and as more likely to produce positive outcomes in students (Curtis et al., 2003).

As previously mentioned, many students within the public education system do not have access to school psychology services. According to official data (PORDATA, 2012), in the 2011-2012 school year, a total of 1,528,197 preschool and school-aged children were attending public schools. Taking into account the average school psychologist-to-student ratio found in public schools, one can estimate that the sample of 383 school psychologists covered 33\% of the students within the public education sector. If this ratio is taken as representing the reality of this sector, and using the official estimate of a total population of 650 school psychologists in the country, one can infer that by the time this study was conducted only $56 \%$ of the preschool and school-aged children were covered by school psychology services. Since the total number of school psychologists in private schools is unknown, this generalization cannot be applied to the private education sector.

Although no recommended value of school psychologistto-school ratio exists at this time, it is clear that the challenge to provide comprehensive quality psychology services increases with the number of schools served (Thomas, 2000). The Portuguese public school network has been recently reorganized, creating more geographically dispersed school clusters, encompassing more school establishments and larger student populations, ranging from preschool to the 12th grade. Implementation of this reorganization needs to be combined with a strong policy to recruit school psychologists, in order to prevent further degrading school psychologist-to-student ratios in public schools. Investing in recruiting and retaining school psychologists is also crucial at a time when compulsory education has been expanded from 9 to 12 years.

The distribution of school psychologists' time among the different activities points to professional practices still being tied to traditional roles. However, contrary to what has been observed in other countries surveyed with ISPS (e.g., China [Hong Kong], Germany, Northern England, Russia, and the United States) (Jimerson et al., 2007) and systematically reported in the United States literature (e.g., Bramlett et al., 2002; Curtis et al., 2008; Curtis et al., 1999; Fagan \& Wise, 2007; Reschly, 2000; Reschly \& Wilson, 1995), Portuguese school psychologists did not report to be primarily engaged in testing or assessment activities. These activities are respectively distinguished by NASP (2003) as the process of administrating and scoring tests versus using a multimethod, multisource, and multisetting approach to gather information for evaluation purposes.

Results not only reflect a balance between the average time spent in evaluation and counseling practices, but also reveal that a considerable amount of practitioner's time is allocated to other professional services, such as vocational guidance. The role of the school psychologist in Portugal has historically been connected to the provision of vocational guidance services. Over the years, several legal documents have reinforced this role, namely concerning screening and referral of at-risk students to vocational education (e.g., Joint Order $n^{\circ} 453 / 2004$, Ordinance ${ }^{\circ} 292-$ $A / 2012$ ). Therefore, it is not surprising that this activity came up as the third most time-consuming professional practice. According to CIDEC (2006), vocational guidance activities tend to be concentrated on students in the 9th and 12th grades, when major academic transitions occur.

Respondents as a whole reported spending less than one-sixth of their total work time with special educationrelated activities. This finding suggests that practitioners in Portugal are less involved in the referral, testing, and placement of students, activities that are central to school psychological practice in the United States. Instead, practitioners seem to engage in a broader service delivery role that addresses all students rather than special education populations. On the other hand, results indicate that a significant amount of the school psychologists' time is spent conducting assessment for purposes other than special education eligibility. 
Although practitioners appear to reach beyond the traditional role of "tester," it seems they struggle to move away from direct remedial intervention functions toward more ecological and prevention-oriented services. Similar to the results in most countries previously surveyed with ISPS (Jimerson et al., 2007; Jimerson et al., 2008; Jimerson et al., 2009), Portuguese school psychologists reported spending limited time in prevention and promoting wellness. The time spent in the provision of indirect services, such as training and consultation with parents and families, teachers and school staff, was also noticeably low. Compared with their colleagues in the majority of those countries, Portuguese school psychologists appear to be relatively less engaged in consultation practices.

Consistent with prior studies (e.g., Bramlett et al., 2002; Jordan et al., 2009; Oakland \& Cunningham, 1992), Portuguese school psychologists' involvement in researchrelated activities is practically nonexistent. Research is considered to be one of the school psychologist's roles and typically identified as very relevant to professional practice by practitioners around the world (e.g., Australia, China [Hong Kong], Cyprus, Greece, New Zealand, Northern England, Russia, Switzerland, and the United States) (Jimerson et al., 2007; Jimerson et al., 2008; Jimerson et al., 2009). However, as Fagan and Wise (2007) emphasized, when called upon to perform so many tasks, research may be seen as less of a priority. Furthermore, these authors remark that schools have not traditionally encouraged or given time for practitioners to conduct research, and even when they do, practitioners may lack the competencies and technical support to carry it out independently.

Practitioners' time distribution among different target audiences also points to a professional practice primarily focused on psychologist-child interaction. This represents what Gutkin and Conoley (1990) call the "Paradox of School Psychology," observing that school psychologists tend to focus their intervention on children, even though to serve them more effectively professionals should first and foremost concentrate their attention and professional expertise on adults (i.e., parents, teachers, and also principals). These authors state that, since the primary environments in which children are functioning, such as home and school, are mainly controlled by adults, intervention focused on children is at best palliative. Therefore, they propose a service delivery model that emphasizes the provision of indirect (e.g., training and consultation) rather than direct services (e.g., counseling and psychotherapy), as the best way to maximize the potential impact of school psychology services, both on the children's significant adults and the children themselves.

Concerning working in schools that offered a wide range of education levels, school psychologists reported focusing on students in the higher education levels rather than on younger children. In this context of wide education levels and inappropriate school psychologist-to-student ratios, practitioners may be restrained by heavy demands and lack of opportunity to implement preventive and early intervention services. Such a deficit-oriented model not only perpetuates a greater demand for school psychologists to assess, diagnose, and treat students' problems (EhrhardtPadgett, Hatzichristou, Kitson, \& Meyers, 2004), but also interferes with the delivery of more effective school psychology services (Sheridan \& Gutkin, 2000).

Although this study has described patterns of activity for Portuguese school psychologists as a whole, it is important to underline that results point to interindividual differences in how practitioners perform their job. As Fagan and Wise (2007, p. 107) observed, "currently no two school psychologists spend their time in exactly the same way," adding that the practice of each individual school psychologist is influenced by a combination of factors, namely personal characteristics, training background, professional skills, and job-site characteristics, which may account for the variability found in this study.

\section{Study Limitations}

This study contributes valuable information about school psychology and school psychologists in Portugal. However, a number of issues should be highlighted and deserve consideration. First, the absence of a complete and updated list of the population under study, as well as their respective contacts, has posed challenges to sampling and data collection. This limitation impaired the use of random sampling methods, which would allow safer generalizations of the results. Though the survey was disseminated throughout the entire public-school network, there are no guarantees that it reached all public-school psychologists, since survey invitations were addressed to the school's board of directors. On the other hand, and despite the efforts to contact as many private schools as possible, the authors are aware that probably not all members of the target population were reached. Not knowing the number of school psychologists working in the private sector also precludes an estimation of the percentage of these practitioners covered in this study. Finally, it is important to note that the results obtained rely on self-reported and retrospective data, which are prone to respondent bias. School psychologists reported their perceptions of how they distribute their working time; however, this is only an estimate, and is susceptible to inaccuracies.

\section{Implications}

This study depicts the current situation of school psychology in Portugal and has identified needs to improve psychological services for students at all education levels. To that end, several implications can be drawn from this study that may have value to school psychologists, their 
employers and trainers, researchers, policy makers, and professional associations.

An immediate practical implication regards the identification of public and private school establishments where school psychological services are available. Additionally, an up-to-date list of the school psychology providers operating in those establishments, with respective professional contacts, should be developed. This information can be crucial to stimulate and design future research on the profession. A related issue is strengthening the network of practitioners to enhance communication and unified action to advance psychological practice in schools. Involving the universities in the establishment and consolidation of this network would have the added value of strengthening practitioner-researcher networks.

Implications for policy can also be derived from this study. A major priority concerns the necessity of improving the employment policies and working conditions of school psychologists, which have degraded over the years. Maintaining this tendency may negatively impact the profession by reducing the appeal of school psychology to students and dispelling more experienced and apt professionals away from the field.

A parallel priority refers to the development of the current policy framework of school psychology services. The legislation regulating these services has not been updated in 20 years, and it needs revision to accompany the evolution of the education system and of the profession itself. Moreover, what is written in the law has not been fully realized in the field. For example, the foreseen multidisciplinary teams and the continuing education of the professionals have not been implemented and services lack guidelines and coordination structures. This development should be coupled with a clear definition of school psychology's scope and functions. The definition of the profession is typically required to delineate its legal status, to assert its credibility next to the public and other professions (Oakland \& Jimerson, 2007), and to set reasonable expectations regarding the profession. Thus, it is important to advance with a national statement that defines the specialty of school psychology and clarifies school psychologists' roles and responsibilities.

As a result of the absence of professional guidelines, the delivery of school psychology services has been left to the discretion of each practitioner and/or school board. This lack of standardization of professional practices hampers the establishment of a cohesive and nationally recognized profession (Jordan et al., 2009). Accordingly, it is essential to develop national guidelines for psychological practice in schools, in order to provide guidance and technical assistance to practitioners, as well as to promote consistency, quality, and excellence of the services provided. Such documents should consider psychologists' ethical obligations, the current legislation impacting the profession, and evidence-based practices.
The information gathered in this study may assist in the development of the aforementioned policies and guidelines. The results show that although school psychologists fill other roles, direct remediative practices that have been dominant throughout the history of the profession are still prevalent in Portuguese school psychology. Future policy frameworks and guidelines should firmly advocate for more comprehensive and prevention-oriented services to help the profession grow in this direction. National recommendations for establishing appropriate and justifiable school psychologist-to-student ratios are missing and need to be produced, in order to clarify those who are unaware of their impact on the nature and quality of the services delivered by school psychologists.

Several issues in the training and professional development of school psychologists should also be addressed. At this level, it is critical to develop national guidelines for university preparation of school psychologists. These guidelines should include expectations for professional knowledge and skills, content of the curriculum, field experience, and practical training. They should reflect the educational and mental health contexts unique to Portugal, and ensure that students acquire a broader range of knowledge and professional skills in the psychology and education domains. International guidelines can be considered when designing such documents (e.g., ISPA, 2009; NASP, 2010). Until these guidelines are available, findings underline the importance of understanding whether the training programs are properly emphasizing and preparing psychology students to provide indirect and preventive services, or if they are contributing to the maintenance of traditional roles by focusing on assessment and clinical processes.

No less important is to establish a model for the continuing education and supervision of the school psychologists already in the field, especially when considering their diverse educational backgrounds. Although continuous education and supervision are routinely offered by universities and private organizations, not all practitioners have access to them due to financial and geographical constraints. Looking at how school psychologists' time is actually spent, there is clearly a need to expand and reinforce, through professional development activities, the professional knowledge and skills in the provision of indirect and preventive services, research, and evaluation activities. Although recommended by law (Decree-law $\mathrm{n}^{\circ}$ 190/91), but never implemented, the celebration of agreements between the Ministry of Education, universities, and scientific and professional associations, is a good principle and would allow for a sustainable development of the profession.

Finally, it is essential to introduce a research agenda for school psychology. Immediate targets for research could include understanding the procedures and methodologies adopted by school psychologists in their areas of 
activity. Equally important is to evaluate the impact and outcomes of the services delivered by school psychologists. The results of these studies can help establish a baseline from which to design plans of action for school psychologists to provide more effective and evidencebased services. Future research should try to clarify the relationships between the professional practices and characteristics of school psychologists and workplace variables. Analysis of professional issues such as training, ethics, job satisfaction, and perceptions about school psychology, is also important to increase the knowledge about the profession in Portugal. In addition, periodic surveys are needed to monitor changes within the profession and to evaluate whether the changes occurring are in a desirable direction. Another related area for research is the study of the impact of new educational policies on school psychologists' work. A recent example is the passage of Decree-law $n^{\circ} 3 / 2008$, which redefined assessment for special education eligibility within the framework and taxonomy of the International Classification of Functioning, Disability, and Health-ICF. An evaluation of the implementation of this law confirmed changes in the identification and assessment of children with special needs, with implications for school psychologists (Sanches-Ferreira et al., 2012), resulting in recommendations of new models for psychological practice in the schools (Simeonsson \& Lee, 2013).

\section{CONCLUSION}

This study advances the knowledge of school psychology in Portugal. Based on a nationwide survey to school psychologists employed in public and private schools, it provides valuable information regarding the practitioners' profiles, their working conditions, and their professional practices. Presently, Portugal is undergoing a severe economic crisis that is impacting school psychology services. It is anticipated that future studies will reveal a deterioration of practitioners' working conditions, which will surely be reflected in professional practices. More than ever, and in the context of an economic crisis, it is important to increase school psychology research in Portugal, not only to provide practitioners opportunities for self-reflection and self-monitoring, but also to demonstrate to key stakeholders the effectiveness of what professionals are doing and that their presence in schools matters.

\section{ACKNOWLEDGEMENTS}

The authors would like to thank all school psychologists who participated in this study and the Directorate-General of Education for supporting data collection.

\section{FUNDING}

This research was financially sponsored by the Portuguese Foundation for Science and Technology (Doctoral grant, SFRH/ $\mathrm{BD} / 78646 / 2011)$.

\section{ABOUT THE AUTHORS}

Sofia A. Mendes received her MSc degree in educational and development psychology from the University of Porto. With five years of professional experience as a school psychologist, she is now working toward her $\mathrm{PhD}$ at the same university.

Isabel Abreu-Lima, $\mathrm{PhD}$, is a professor of educational psychology and psychological intervention in educational settings at the University of Porto. Her main research interests are preschool math intervention and parental education.

Leandro S. Almeida, $\mathrm{PhD}$, is a full professor of educational psychology at the University of Minho (Braga-Portugal). His main topics of research concern the role of psychological variables on learning and academic success. He has served as president of the Portuguese Psychologists Association for 10 years. He is the author of several chapters and papers in Portuguese, Spanish, and English editions.

Rune J. Simeonsson, $\mathrm{PhD}, \mathrm{MSPH}$, is a psychologist with appointments as professor of education and fellow at the FPG Child Development Institute at the University of North Carolina at Chapel Hill. He is also affiliated with Jönköping University, Sweden, and the University of Porto, Portugal. His academic and research interests reflect developmental studies, disability, and public health.

\section{REFERENCES}

Almeida, L. S. (2003). Psicologia escolar em Portugal [School psychology in Portugal]. In S. N. Neves (Ed.), Psicologia em Portugal (pp. 13-44). Coimbra, Portugal: Quarteto Editora.

Bramlett, R. K., Murphy, J. J., Johnson, J., Wallingsford, L., \& Hall, J. D. (2002). Contemporary practices in school psychology: A national survey of roles and referral problems. Psychology in the Schools, 39(3), 327-335. doi:10.1002/pits. 10022

Castillo, J. M., Curtis, M. J., \& Gelley, C. (2012). School psychology 2010 School psychologists' professional practices and implications for the field. Communiqué, 40(8), 4-6.

Centro Interdisciplinar de Estudos Económicos. (2006). Estudo sobre a intervenção no contexto escolar dos serviços de psicologia e orientação [Study about intervention in school context of psychology and guidance services]. Lisboa: Direção Geral de Inovação e Desenvolvimento Curricular.

Curtis, M. J., Grier, J. E., \& Hunley, S. A. (2003). The changing face of school psychology: Trends in data and projections for the future. School Psychology Quarterly, 18(4), 409-430. doi:10.1521/scpq.18.4.409.26999

Curtis, M. J., Lopez, A. D., Castillo, J. M., Batsche, G. M., Minch, D., \& Smith, J. C. (2008). The status of school psychology: Demographic characteristics, employment conditions, professional practices, and continuing professional development. Cоттипiqué, 36(5), 27-29.

Curtis, M. J., Walker, K. J., Hunley, S. A., \& Baker, A. C. (1999). Demographic characteristics and professional practices in school psychology. School Psychology Review, 28(1), 104-116. 
D’Amato, R. C., Van Schalkwyk, G. J., Zhao, B. Y., \& Hu, J. (2013). Understanding the development of school psychology in mainland China. School Psychology International, 34(2), 131-144. doi:10.1177/ 0143034312453392

Decree-law $n^{\circ} 46 / 86$ of 14th October 1986: Establishes the general framework of the education system.

Decree-law n ${ }^{\circ}$ 190/91 of 17th May 1991: Decrees the creation, nature, and attributions of psychology and guidance services.

Decree-law $n^{\circ} 3 / 2008$ of 7 th January 2008: Defines the support to be provided to students with special education needs.

Decree-law n ${ }^{\circ}$ 57/2008 of 4th September 4 2008: Creates the Portuguese Order of Psychologists and approves its statute.

Dillman, D., Smith, J., \& Christian, L. (2009). Internet, mail and mixedmode surveys: The tailored design method (3rd ed.). New York: Wiley.

Ehrhardt-Padgett, G. N., Hatzichristou, C., Kitson, J., \& Meyers, J. (2004). Awakening to a new dawn: Perspectives of the future of school psychology. School Psychology Review, 33(1), 105-114.

European Commission. (2013). The Bologna process: Towards the European higher education area. Retrieved from http://ec.europa.eu/ education/higher-education/bologna_en.htm

Fagan, T. K., \& Wise, P. S. (2007). School psychology: Past, present and future (3rd ed.). Bethesda, MD: National Association of School Psychologists.

Gutkin, T. B., \& Conoley, J. C. (1990). Reconceptualising school psychology from a service delivery perspective: Implications for practice, training, and research. Journal of School Psychology, 28, 203-223.

Inácio, I. (2012, August 11). Ministério da educação mantém número de vagas para psicólogos [Ministry of education mantains the number of positions for psychologists]. Jornal de notícias, 1-6.

International School Psychology Association. (2009). The ISPA standards for accrediting professional training programs in school psychology. Retrieved from http://www.ispaweb.org/

Jimerson, S. R., Graydon, K., Curtis, M. J., \& Staskal, R. (2007). The international school psychology survey: Insights from school psychologists around the world. In S. R. Jimerson, T. D. Oakland, \& P. T. Farrell (Eds.). The handbook of international school psychology (pp. 453-463). London, England: Sage.

Jimerson, S. R., Graydon, K., Skokut, M., Alghorani, M. A., Kanjaradze, A., Forster, J., \& the ISPA Research Committee. (2008). The international school psychology survey: Data from Georgia, Switzerland and the United Arab Emirates. School Psychology International, 29(1), 5-28. doi:10.1177/0143034307088501

Jimerson, S. R., Annan, J., Skokut, M., \& Renshaw, T. L. (2009). Educational psychology in New Zealand: Results of the 2006 international school psychology survey. School Psychology International, 30(5), 443-455. doi:10.1177/0143034309341617

Joint Order $n^{\circ} 453 / 2004$ of 27th June 2004: Regulates the creation of adult education and training courses with dual certification, aimed at youth aged 15 years old or over.

Jordan, J. J., Hindes, Y. L., \& Saklofske, D. H. (2009). School psychology in Canada: A survey of roles and functions, challenges and aspirations. Canadian Journal of School Psychology, 24(3), 245-264. doi:10.1177/ 0829573509338614

Leitão, L. M., Paixão, M. P., Silva, J. T., \& Miguel, J. P. (2001). Ser psicólogo em contexto escolar: Os serviços de psicologia e orientação na região centro [To be a psychologist in the school context: The psychology and guidance services in central Portugal]. Psychologica, 26, 27-53.

Lewis, M. F., Truscott, S. D., \& Volker, M. A. (2008). Demographics and professional practices of school psychologists: A comparison of NASP members and non-NASP school psychologists by telephone survey. Psychology in the Schools, 45, 467-482. doi:10.1521/scpq.18.4.409. 26999

Mendes, S. A., Abreu-Lima, I., \& Almeida, L. S. (2013). Psicólogos escolares em Portugal: Contributo para a sua caracterização profissional [School psychologists in Portugal: Contribution to professionals' characterization]. Psicologia, Educação e Cultura, 17(1), 190-208.

National Association of School Psychologists. (2003). NASP position statement on school psychologists' involvement in the role of assessment. Bethesda, MD: Author. Retrieved from http://nasponline.org/ information/pospaper_assess.html

National Association of School Psychologists. (2010). Model for comprehensive and integrated school psychological services. Retrieved from http://www.nasponline.org/standards/2010standards.aspx

Oakland, T. D., \& Cunningham, J. L. (1992). A survey of school psychology in developed and developing countries. School Psychology International, 13(2), 99-130.

Oakland, T. D., \& Jimerson, S. R. (2007). School psychology internationally: A retrospective view and influential conditions. In S. R. Jimerson, T. D. Oakland, \& P. T. Farrell (Eds.), The handbook of international school psychology (pp. 453-463). London: Sage.

Ordinance $\mathrm{n}^{\circ}$ 292-A/2012 (2012, September 26). Launches a pilot experiment to offer vocational courses in elementary education.

PORDATA. (2012). Non higher education students. Retrieved from http:// www.pordata.pt/en/Subtheme/Portugal/Non+ Higher+Education + Students-75

Raviv, A., Mashraki-Pedhatzur, S., \& Erhard, R. (2002). The Israeli school psychologist: A professional profile. School Psychology International, 23(3), 283-306. doi:10.1177/0143034302023003233

Reschly, D. J. (2000). The present and future status of school psychology in the United States. School Psychology Review, 29, 507-522.

Reschly, D. J., \& Wilson, M. S. (1995). School psychology practitioners and faculty: 1986 to 1991-92 trends in demographics, roles, satisfaction, and system reform. School Psychology Review, 24, 62-80.

Sanches-Ferreira, M., Simeonsson, R. J., Silveira-Maia, M., Alves, S., Tavares, A., \& Pinheiro, S. (2012). Portugal's special education law: Implementing the international classification of functioning, disability and health in policy and practice. Disability and Rehabilitation, 35(10), 868-873. doi:10.3109/09638288.201 2.7088/6

Schalkwyk, G. J. V., \& D’Amato, R. C. (2013). Providing psychological services and counselling in Pacific Rim countries: Where is school psychology in Asia? School Psychology International, 34(2), 123-130. doi: $10.1177 / 0143034312453389$

Sheridan, S. M., \& Gutkin, T. B. (2000). The ecology of school psychology: Examining and changing our paradigm for the 21st century. School Psychology Review, 29, 485-502.

Simeonsson, R. J., \& Lee, A. S. (2013). The ICF-CY: A universal taxonomy for psychological assessment. In V. Schwean \& D. Saklofske (Eds.), Handbook of psychological assessment of children and adolescents (pp. 453-463). Oxford, England: Oxford University Press.

Thomas, A. (2000). School psychology 2000: What is average? Communiqué, 28(8), 34.

Trombetta, C., Alessandri, G., \& Coyne, J. (2008). Italian school psychology as perceived by Italian school psychologists: The results of a national survey. School Psychology International, 29(3), 267-285. doi: $10.1177 / 0143034308093672$

Wang, Y., \& D'Amato, R. C. (2013). Understanding the development of school psychology services in the Republic of Taiwan. School Psychology International, 34(2), 145-153. doi:10.1177/0143034312453394 